\title{
Relation between gastric emptying rate and energy intake in children compared with adults
}

\author{
B D Maes, Y F Ghoos, B J Geypens, M I Hiele, P J Rutgeerts
}

\begin{abstract}
Measurement of gastric emptying rate of solids in children is difficult because the available methods are either invasive or induce a substantial radiation burden. In this study the newly developed ${ }^{13} \mathrm{C}$ octanoic acid breath test was used to examine the gastric emptying rate of solids and milk in healthy children and to compare gastric emptying in children and adults. Fifteen healthy children and three groups of nine healthy adults were studied, using three different test meals labelled with $50 \mathrm{mg}$ of ${ }^{13} \mathrm{C}$ octanoic acid: a low caloric pancake (150 kcal), a high caloric pancake $(250 \mathrm{kcal})$, and $210 \mathrm{ml}$ of milk (134 kcal). Breath samples were taken before and at regular intervals after ingestion of the test meal, and analysed by isotope ratio mass spectrometry. The gastric emptying parameters were derived from the ${ }^{13} \mathrm{CO}_{2}$ excretion curves by nonlinear regression analysis. No significant difference was found between children and adults in the emptying rate of the low caloric solid test meal. In children as well as in adults, increasing the energy content of the solid meal resulted in a significantly slower emptying rate. The milk test meal, however, was emptied at a faster rate in adults and at slower rate in children compared with the low caloric solid test meal. Moreover, the emptying rate of milk in children was significantly slower than in adults. In conclusion, a similar gastric emptying rate of solids but a slower emptying of full cream milk was shown in children of school age compared with adults, using the non-radioactive ${ }^{13} \mathrm{C}$ octanoic acid breath test.

(Gut 1995; 36: 183-188)
\end{abstract}

Keywords: gastric emptying, energy intake.

Department of

Medicine, Division of Gastroenterology and Gastrointestinal

Research Centre, University Hospital Gasthuisberg, Leuven, Belgium

B D Maes

Y F Ghoos

B J Geypens

M I Hiele

P J Rutgeerts

Correspondence to: Professor Dr P J Rutgeerts, Professor Dr PJ Rutgeerts, Medical Research, University Hospital Gasthuisberg, Hospital Gasthuisberg,
B-3000 Leuven, Belgium B-3000 Leuven, Belgium

Accepted for publication 9 June 1994

Gastric emptying in children is difficult to evaluate properly. The main reason is the lack of safe and non-invasive methods to measure gastric emptying rate in children. All methods used until now have some disadvantages for routine gastric emptying studies in children: intubation studies are invasive and time consuming, radioscintigraphic methods cause a substantial radiation burden to the patient, ultrasonographic evaluation of gastric emptying rate can only be applied to liquid test meals and is largely dependent on the experience of the investigator. Therefore the impact of delayed gastric emptying rate on nutrient assimilation and nutritional state or the role of gastric emptying rate in symptoms such as chronic abdominal pain, nausea, and vomiting are largely unexamined in children. ${ }^{1-5}$

Recently, we developed a carbon labelled breath test to measure gastric emptying rate of solids, based on the characteristics of octanoic acid. ${ }^{6}$ Using a solid standard test meal of 250 $\mathrm{kcal}$ consisting of a labelled egg and two slices of white bread, an excellent correlation between the gastric emptying results of the radioscintigraphic method (lag phase, half emptying time) and those of the breath test (gastric emptying coefficient, lag phase, and half emptying time) could be shown in adults. ${ }^{6}$ It was also shown that day to day variability of gastric emptying rate of solids, obtained by the carbon labelled octanoic acid breath test is comparable with data obtained by radioscintigraphy, ${ }^{6}$ and that the breath test was sensitive enough to detect pharmacological influences of erythromycin and propantheline on gastric emptying rate of solids. ${ }^{7}$

The aim of this study was to evaluate the gastric emptying rate in children using ${ }^{13} \mathrm{C}$ octanoic acid labelled test meals and to compare gastric emptying in children with gastric emptying in adults.

\section{Methods}

SUBJECTS

Fifteen healthy children performed three gastric emptying studies using three different test meals within one month in a randomly allocated sequence. Nine of the children were girls, six were boys; the mean age was 9 years, ranging from 4 to 15 . The mean weight was $31 \mathrm{~kg}$, ranging from 17 to 65 and the mean height was $135 \mathrm{~cm}$, ranging from 105 to 165 . Table I gives detailed description of the children. Twenty seven adults, divided into
TABLE I Characteristics of the examined children

\begin{tabular}{|c|c|c|c|c|c|}
\hline Child & $\begin{array}{l}\text { Weight } \\
\text { (kg) }\end{array}$ & $\begin{array}{l}\text { Height } \\
(\mathrm{cm})\end{array}$ & $\begin{array}{l}\text { Age } \\
\text { (y) }\end{array}$ & Sex & $\begin{array}{l}B S A \\
\left(m^{2}\right)\end{array}$ \\
\hline $\mathrm{Cl}$ & 32 & 143 & 11 & $\mathbf{M}$ & $1 \cdot 12$ \\
\hline C2 & 36 & 147 & 11 & M & 1.21 \\
\hline C3 & 38 & 143 & 10 & $\mathrm{~F}$ & 1.23 \\
\hline $\mathrm{C} 4$ & 41 & 163 & 14 & $\mathbf{F}$ & 1.35 \\
\hline C5 & 17 & 105 & 4 & $M$ & 0.70 \\
\hline C6 & 27 & 141 & 9 & $\mathrm{~F}$ & 1.02 \\
\hline C7 & 20 & 123 & 6 & $F$ & 0.82 \\
\hline C8 & 24 & 122 & 6 & $\mathbf{M}$ & 0.90 \\
\hline C9 & 28 & 134 & 9 & $\mathbf{F}$ & 1.01 \\
\hline $\mathrm{C} 10$ & 65 & 165 & 15 & $F$ & 1.73 \\
\hline C11 & 39 & 142 & 10 & $\mathbf{F}$ & $1 \cdot 24$ \\
\hline $\mathrm{C} 12$ & 20 & 116 & 7 & $M$ & 0.80 \\
\hline $\mathrm{C} 13$ & 37 & 133 & 10 & $\mathbf{F}$ & $1 \cdot 18$ \\
\hline $\mathrm{C} 14$ & 25 & 132 & 7 & $\mathrm{~F}$ & 0.95 \\
\hline C15 & 21 & 115 & 5 & $\mathbf{M}$ & 0.82 \\
\hline
\end{tabular}

BSA: body surface area. 
TABLE II Characteristics of the examined adults, according to the ingested test meal (mean and interquartile range)

\begin{tabular}{llllll}
\hline Test meal & Female/male & Weight $(\mathrm{kg})$ & Height $(\mathrm{cm})$ & Age $(y)$ & BSA $\left(\mathrm{m}^{2}\right)$ \\
\hline $150 \mathrm{kcal}$ & $5 / 4$ & $61(60-78)$ & $177(168-182)$ & $23(21-24)$ & $1 \cdot 70(1 \cdot 69-2 \cdot 00)$ \\
$250 \mathrm{kcal}$ & $5 / 4$ & $62(57-74)$ & $168(168-172)$ & $22(19-23)$ & $1 \cdot 66(1.56-1 \cdot 77)$ \\
Milk & $5 / 4$ & $60(57-76)$ & $167(162-176)$ & $20(18-22)$ & $1 \cdot 63(1.56-1 \cdot 91)$ \\
\hline
\end{tabular}

BSA: body surface area.

three groups of five women and four men, each performed one gastric emptying study using one of the three test meals. Table II summarises the characteristics of the adult groups. The test meal of each adult group was allocated at random. None of the children or adults had gastrointestinal complaints, a medical or surgical gastrointestinal history or was taking any drugs. The study protocol was approved by the ethics committee of the University of Leuven. Informed consent was obtained from all the subjects or their parents.

\section{MATERIALS}

All gastric emptying studies were performed after an overnight fast at 8 am with the children quietly seated in front of a video tape, and three children, who could not eat the test meal within 10 minutes, were excluded.

The low caloric solid test meal was based on a pancake made of $5 \mathrm{~g}$ of sugar, $12.5 \mathrm{~g}$ of flour, $10 \mathrm{~g}$ of full cream milk, and one egg. Half of the egg yolk was baked separately after $50 \mathrm{mg}$ of ${ }^{13} \mathrm{C}$ octanoic acid (Isotec, Ohio, USA) was solubilised in the yolk by mixing. The paste was baked around the labelled half of the egg yolk. Total energy content of the test meal was $150 \mathrm{kcal}(9 \mathrm{~g}$ of proteins, $13 \mathrm{~g}$ of carbohydrates, and $7 \mathrm{~g}$ of fat).

The high caloric solid test meal consisted of two pancakes; one was a labelled pancake as described above (150 kcal) and one was an unlabelled pancake baked with the same ingredients apart from the separately baked half egg yolk (100 kcal). Total energy content was $250 \mathrm{kcal}$ (14 g of proteins, $26 \mathrm{~g}$ of carbohydrates, and $10 \mathrm{~g}$ of fat). Both solid test meals were consumed within a 10 minute period. The subjects were allowed to drink $150 \mathrm{ml}$ of water during the test meal.

The liquid test meal used in the third study consisted of $210 \mathrm{ml}$ of full cream milk in which $50 \mathrm{mg}$ of ${ }^{13} \mathrm{C}$ octanoic acid was solubilised. The energy content of this liquid test meal was $134 \mathrm{kcal}$, containing $7 \mathrm{~g}$ of proteins, $10 \mathrm{~g}$ of carbohydrates, and $7 \mathrm{~g}$ of fat. The liquid test meal was consumed within five minutes.

\section{MEASURING TECHNIQUES}

Breath samples were taken before intake of the test meal and every 15 minutes after ingestion of the meal up to four hours to study the gastric emptying rate of the solid test meals. The gastric emptying rate of the liquid test meal was examined by taking breath samples before the meal and every 10 minutes during a three hour period for children and during a two hour period for adults. Breath was collected in a 3 litre aluminium coated plastic bag
(Tesseraux, Bürstadt, Germany), from which aliquots were taken to determine ${ }^{13} \mathrm{C}$ enrichment with an isotope ratio mass spectrometer (model 250, Finigan MAT, Bremen, Germany and ABCA, Europa Scientific, Lowe, England). The results were expressed as the percentage of ${ }^{13} \mathrm{C}$ recovery per hour. The carbon dioxide production was assumed to be $300 \mathrm{mmol} / \mathrm{m}^{2}$ body surface area per hour. Body surface area was calculated by the weight-height formula of Haycock et al. ${ }^{8}$

\section{MATHEMATICAL ANALYSIS}

The ${ }^{13} \mathrm{CO}_{2}$ excretion in breath, expressed as percentage dose per hour was further mathematically analysed using two non-linear regression equations (SAS: PROC $\mathrm{NLIN}^{9}$ or with a home made program written for EXCEL 4.0 (G Mys, personal communication)) to find the best fitting curve through the measured data points. The first formula is given by:

$$
\text { (I) } y=a t^{b} e^{-c t}
$$

where $y$ is the percentage of ${ }^{13} \mathrm{CO}_{2}$ excretion in breath per hour; $t$ is time in hours; and $a, b$, and $c$ are constants. The second formula is expressed as:

$$
\text { (II) } \mathrm{y}=\mathrm{mk} \beta \mathrm{e}^{-\mathrm{kt}}\left(1-\mathrm{e}^{-\mathrm{kt}}\right)^{\beta-1}
$$

where $y$ is the percentage of ${ }^{13} \mathrm{C}$ excretion in breath per hour; $t$ is time; $m, k$, and $\beta$ are constants and $m$ is the total cumulative ${ }^{13} \mathrm{C}$ recovery when time is infinite. This formula is the first derivative of the modified power exponential formula of Siegel et al ${ }^{10}$ with a correction factor $\mathrm{m}$. Three parameters of gastric emptying were derived from these formulas, based on regression models obtained by simultaneous radioscintigraphic and breath test measurements ${ }^{6}$ :

(1) The gastric emptying coefficient (GEC), corresponding to $\ln (a)$ of the first formula and a global index for the gastric emptying rate.

(2) $T_{1 / 2}$, the breath test determined gastric half emptying time (in minutes), by the following equation derived from the first formula:

$$
t_{1 / 2}=[60(\text { gamma inv }(0 \cdot 5 ; b+1 ; 1 / c)-66] / 1 \cdot 12
$$

or by the following equation using the second formula:

$$
t_{1 / 2}=\left[60(-1 / k) \ln \left(1-2^{-1 / \beta}\right)-66\right] / 1 \cdot 12
$$

(3) The lag phase. The lag phase is defined as was done by Siegel et $a l,{ }^{11}$ as the time (in minutes) at the point of inflection of the curve after mathematical integration - that is, the time of maximal ${ }^{13} \mathrm{CO}_{2}$ excretion of the fitted curve, calculated by the following equation derived from the first formula:

$$
t_{\max }=[60(b / c-66] / 0.94
$$

or by the following equation using the second formula:

$$
t_{\max }=[60(\ln \beta) / k-66] / 0.94
$$


The gastric half emptying time and the lag phase are - by the nature of their mathematical definition - completely determined by the shape of the curve and thus independent of the endogenous carbon dioxide production.

\section{STATISTICAL EVALUATION}

Gastric emptying parameters of the three series of studies in children and in adults were analysed by descriptive statistical methods (SAS: PROC UNIVARIATE ${ }^{9}$ ). Because of a skew distribution, median and interquartile range are given. The gastric emptying parameters of each child were compared in a non-parametrical paired way for the low and high energy solid test meal, and for the low energy solid test meal and the liquid test meal using the signed rank test (SAS: PROC UNIVARIATE). The gastric emptying parameters of the three adult groups were compared using the non-parametric Mann-Whitney-Wilcoxon test (SAS: PROC NPAR1WAY). Non-parametric methods (SAS: PROC NPAR1WAY: Mann-WhitneyWilcoxon) were also used to compare the gastric emptying parameters in children and adults for the meals with the same energy load.

\section{Results}

\section{CHILDREN}

Figure 1 shows the mean ${ }^{13} \mathrm{CO}_{2}$ excretion data of all children and the corresponding fitting curves after ingestion of the low and high energy solid test meal and after the liquid test meal. Increasing the volume of the solid test meal with the same meal composition, changed the excretion curve by a peak excretion not only lower $(8.28(3.2) \% / \mathrm{h}$ (mean (SD)) versus $11 \cdot 17(2 \cdot 56) \% / \mathrm{h})$ and later $(120$ versus $105 \mathrm{~min}$ ), but also by a decreased ascending and descending slope of the curve. Changing the low energy solid test meal by $210 \mathrm{ml}$ of full cream milk resulted in a slightly steeper ascending slope of the excretion curve, but a decreased descending slope of the curve and a lower peak excretion $(9 \cdot 74(3 \cdot 18) \% / h$ versus $11 \cdot 17(2 \cdot 56) \% / \mathrm{h})$ of at about the same time (105 min).

In Fig 2, the individual gastric emptying coefficients, gastric half emptying times, and

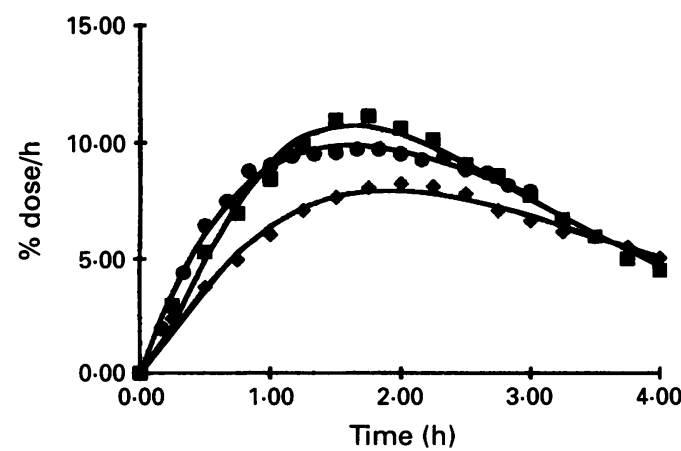

Figure 1: Mean ${ }^{13} \mathrm{CO}_{2}$ excretion in function of time in children after ingestion of a solid test meal of $150 \mathrm{kcal}$ () and $250 \mathrm{kcal}(\diamond)$ and a liquid milk meal (O) and the corresponding fitting curves (solid lines).
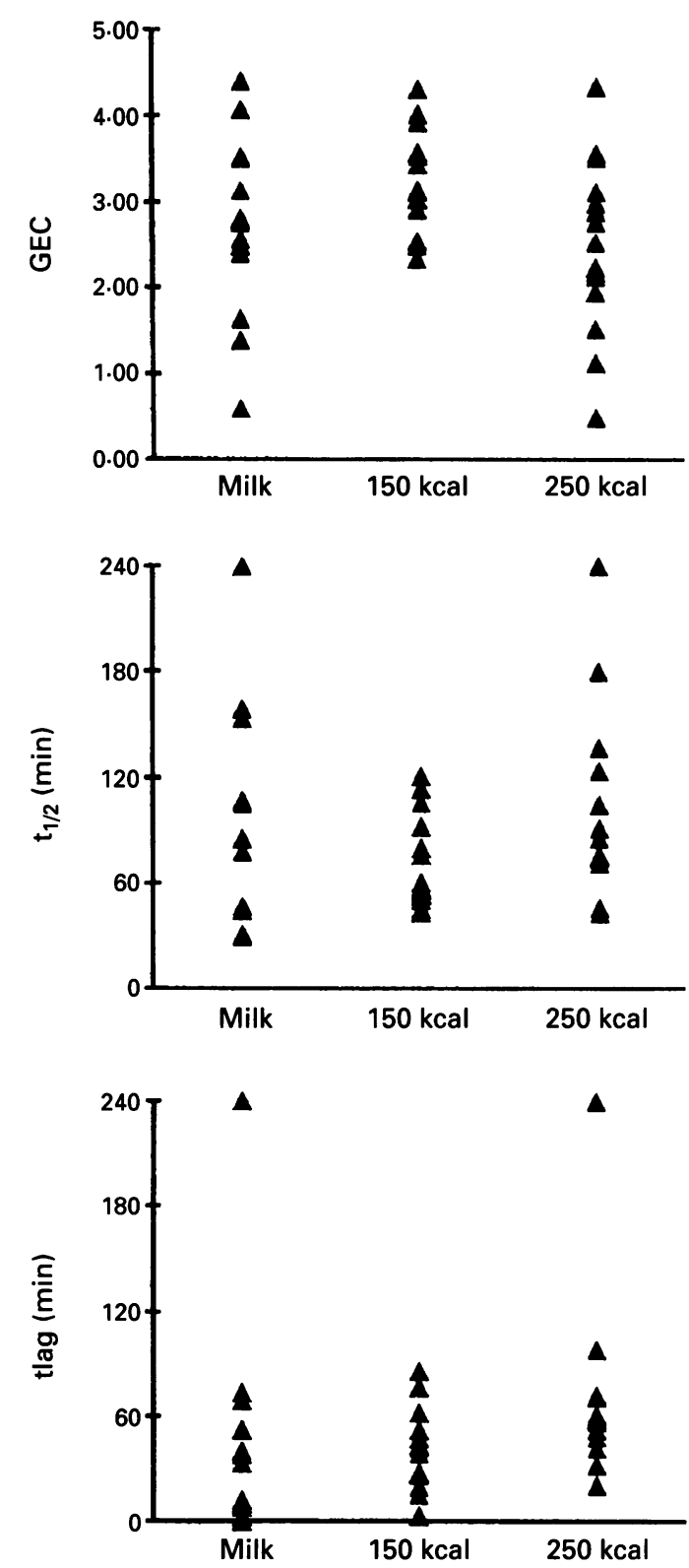

Figure 2: Individual gastric emptying results in children in the three test conditions.

lag phases are displayed for the three different test meals in children. Comparing the $250 \mathrm{kcal}$ solid test meal with the $150 \mathrm{kcal}$ solid test meal, there was a decrease of the gastric half emptying coefficient in all but two children; an increase of the half emptying time was measured in all but these two children. In three of the children the increase was beyond the 240 minutes limit. The lag phase was increased in 11 of 15 examined children. In three children, the gastric emptying rate was too slow to calculate a correct lag phase; a cut off was taken at 240 minutes. A larger variability in gastric emptying results of the high energy test meal was noticed (see also Table III). The emptying of the high energy test meal was statistically significantly slower for all gastric emptying parameters (GEC: $p=0.0015 ; t_{1 / 2}$ : $p=0.0084$; tlag: $p=0.0215$ ).

In 12 of 15 children examined, the gastric emptying coefficient was decreased and the half emptying time increased after ingestion of the milk test meal compared with the $150 \mathrm{kcal}$ solid test meal, pointing to a slower emptying 
TABLE III Gastric emptying results in children and adults (median and interquartile range)

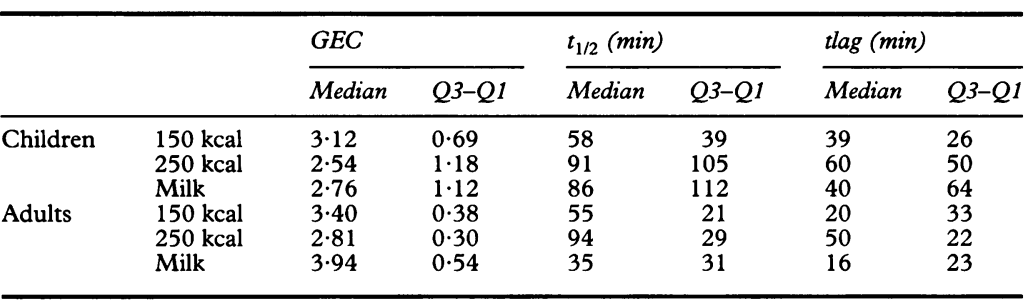

rate of the first meal (Fig 2). In three children, the decrease of the gastric emptying coefficient and the increase of the gastric half emptying time was remarkably large. The lag phase, however, was only increased in eight of the investigated children. Again, the variability of the emptying results in the milk test meal was very large compared with the low energy solid test meal. Paired comparison showed that the differences between the two meals were statistically significant for the gastric emptying coefficient $(p=0.0366)$ and the half emptying time $(p=0.0151)$, but the lag phase was similar $(p=0 \cdot 5245)$.

Comparing the milk and high energy solid test meal, a globally similar emptying rate with an equally high variability was seen in children (see Table III). No gastric emptying parameter showed a statistical difference for these two meals (GEC: $p=0.4887 ; t_{1 / 2}: p=1$; tlag: $\mathrm{p}=0 \cdot 2958)$.

\section{ADULTS}

Figure 3 shows the mean ${ }^{13} \mathrm{CO}_{2}$ excretion data of the three groups of adults and the corresponding fitting curves after ingestion of the corresponding test meal. The results are similar to those obtained in children for the $150 \mathrm{kcal}$ and $250 \mathrm{kcal}$ solid test meal, but a much faster pattern of ${ }^{13} \mathrm{CO}_{2}$ excretion and corresponding gastric emptying is seen after ingestion of the milk test meal. The peak excretion of the curves was $13.25(2.58) \% / \mathrm{h}$ at 105 minutes, $10.94(1.75) \% / h$ at 120 minutes, and $13.48(3.42) \% / \mathrm{h}$ at 60 minutes for the low energy, high energy, and milk test meal, respectively.

In Fig 4, the individual gastric emptying values for the three different test meals examined in adults are given. A gradual increase of the energy content of the meal

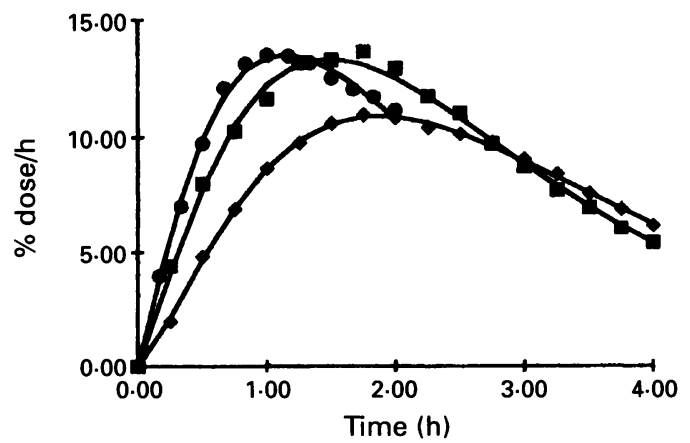

Figure 3: Mèan ${ }^{13} \mathrm{CO}_{2}$ excretion in function of time in adults after ingestion of a solid test meal of $150 \mathrm{kcal}(\square)$ and $250 \mathrm{kcal}(\diamond)$ and a liquid milk meal (O) and the corresponding fitting curves (solid lines).

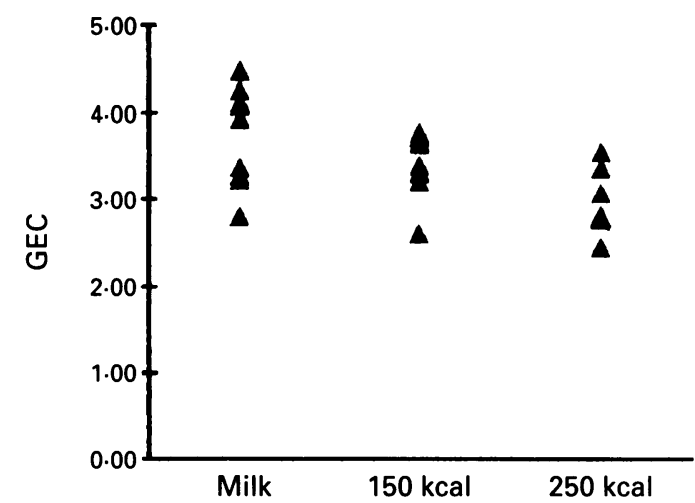

CHILDREN VERSUS ADULTS

Table III shows that gastric emptying of the low (GEC: $p=0 \cdot 1286 ; t_{1 / 2}: p=0.2372$; tlag: $\mathrm{p}=0.0851)$ and high energy solid test meal (GEC: $\quad p=0 \cdot 1165 ; \quad t_{1 / 2}: \quad p=0.2751 ;$ tlag: $\mathrm{p}=0.0604)$ in children and adults is very 
similar. In contrast with solids, the emptying rate of the liquid milk test meal is significantly slower in children than in adults (GEC: $p=0.0048 ; t_{1 / 2}: p=0.0052$; tlag: $\left.p=0.0180\right) . A$ greater variability in gastric emptying rate, however, was seen in children compared with adults in the liquid milk and the high energy solid test meal (Figs 2 and 4).

\section{Discussion}

The gastric emptying rate of solids in children is difficult to evaluate. From the age of three years, all children are receiving an 'adult' diet, consisting of solids as an important energy source. Therefore, an accurate evaluation of the gastric motor function (that is, the ability to mix, grind, and evacuate the ingested meal) of children of school age should be performed using a solid test meal. However, there are two important problems.

Firstly, the volume/energy content of the solid test meal should be adjusted to the body surface area or lean body weight, not only for children but also for adults. As, from the practical view point, this correction is difficult to perform for solid test meals, the use of standard solid test meals is widespread, both in adults and children of school age. ${ }^{11} 12$ In this study, the emptying rate of two standardised solid test meals and one standardised liquid test meal was evaluated in children of school age, and compared with the emptying rate of the same meals in adults. Secondly, until now, the radioscintigraphic technique is the only available method to measure accurately the gastric emptying rate of solids in children despite the radiation hazard. In this study gastric emptying rate was measured using the newly developed ${ }^{13} \mathrm{C}$ labelled octanoic acid breath test, inducing no radiation at all.

The second technique can describe gastric emptying rate of a standard solid test meal in an accurate and reliable way, including the biphasic nature of gastric emptying of solids. ${ }^{67}$ However, some additional methodological considerations have to be made for this study. The solid test meal used in this study consisted of a pancake to ameliorate the palatability of the meal for children. Despite the labelling technique (a labelled egg yolk, which is baked separately) and a meal composition that remained unchanged, the viscosity of the test meal was not the same as the meal described earlier. ${ }^{67}$ Furthermore, the ${ }^{13} \mathrm{C}$ octanoic acid breath test is an indirect method to measure gastric emptying of solids. Although direct measurements on metabolism of octanoic acid have never been done in infants, several reports showed that the oxidation rate of trioctanoin is similar in children and adults. ${ }^{13} 14$

Moreover, as the gastric half emptying time and the lag phase are independent of endogenous carbon dioxide production, differences in basal metabolism between children and adults have no influence on these results. Also, other external influences were excluded. Day to day variability in gastric emptying rate is very well known in adults (similar in scintigraphic and breath test technology ${ }^{6}$ ), but has never been examined in children with none of the existing methods. As we did not study the children at different times using the same test meal, intrasubject variability of test results in children could also not be evaluated; but confounding by day to day variability was eliminated as much as possible by randomising the sequence of test meal administration.

Concerning the adult groups, the three gastric emptying parameters described, changed unidirectly with increasing energy load of the test meal. This further validates the breath test for measurement of gastric emptying of solids. A larger variability in gastric emptying results was seen with the liquid milk test meal of $134 \mathrm{kcal}$.

In children, the gastric emptying results obtained with the low energy solid test meal are comparable with those obtained in adults, however, with a larger variability of results. Increasing the energy content of the meal resulted in a slower gastric emptying pattern similar to adult gastric emptying in 12 of 15 children examined. Three of the children showed an extremely delayed gastric emptying, which seemed to be blocked once a certain plateau of energy load is reached. No relation with age, weight, length, body surface area or sex, however, could be found.

Changing the low energy solid test meal by a liquid fat emulsion with less energy value resulted in children in a slower gastric emptying of the test meal, apart from the lag phase (Table III). The reason for a slower gastric emptying of milk in children is not very clear. No difference in emptying results of the milk test meal were obtained if the calculations were based on the ${ }^{13} \mathrm{CO}_{2}$ excretion data of the first two hours, as performed in adults. Milk leads to the formation of separate gastric food phases because casein is precipitated below a $\mathrm{pH}$ of $4 \cdot 1$ to form curds, ${ }^{15-17}$ which are probably emptied as solid particles. A similar finding has been made in gastrostomy fed patients with spastic quadriplegia, in which whey based milk formulas showed a significantly shorter emptying time than a casein based formula. ${ }^{18}$ However, curd formation of casein in the stomach also occurs in adults. The emptying rate of milk has never been compared between children and adults. A factor of unknown influence, is the effect of liberated opioid peptides during digestion of casein ${ }^{19-21}$ on gastric motility by direct action with gut opiate receptors. It is possible that the gut is more sensitive to the inhibitory action of these opioid peptides during childhood. Or the role of cholecystokinin in the regulation of gastric emptying ${ }^{22}$ may be different in children compared with adults. It is known that casein induces a considerable release of cholecystokinin, at least in animal experiments. ${ }^{2324}$ The release of cholecystokinin in response to casein may vary differentially in adults and children or the receptor density may be different in children. Further validation on this point will be necessary.

The ${ }^{13} \mathrm{C}$ octanoic acid breath test to measure gastric emptying in children has some important advantages over other existing techniques: it is 
non-invasive, causing no radiation at all, the test can be performed in a place and at a time causing a minimum of stress for the child, as the carbon dioxide samples can be collected away from the analytical unit and the test can even be repeated several times within a short period of time.

We conclude that the ${ }^{13} \mathrm{C}$ labelled octanoic acid breath test is a comfortable and promising technique to evaluate gastric emptying in children. Further studies will be necessary to investigate (a) intraindividual variability of test results in children and (b) the best test meal for accurate discrimination between normal and delayed gastric emptying.

1 Gryboski JD, Burger JA, McCallum R, Lange R. Gastric emptying in childhood inflammatory bowel disease: nutri-
tional and pathological correlates. Gastroenterology 1992; tional and path $1148-53$.

2 Kelts DG, Grand RJ, Shen G, Watkins JB, Werlin SL, Bochme C. Nutritional basis of growth failure in children and adolescents with Crohn's disease. Gastroenterology 1979; 76: 720-7.

3 Franco VH, Collares EF, Troncon LE. Gastric emptying in children. Studies on kwashiorkor and on marasmic kwashiorkor. Arquivos de Gastroenterologia 1986; 23: 42-6.

4 Papaila JG, Wilmot D, Grosfeld JL, Rescorla FJ, West KW, Vana DW. Increased incidence of delayed gastric emptying in children with gastroesophageal reflux. A prospective ing in children with gastroesophageal reflux.

5 Woolridge MW, Fisher C. Colic, 'overfeeding', and symptoms of lactose malabsorption in the breast-fed baby: a possible artefact of feed management? Lancet 1988; ii: 382-4.

6 Ghoos Y, Maes B, Geypens B, Mys G, Hiele M, Rutgeerts $\mathrm{P}$, et al. Measurement of gastric emptying rate of solids by means of a carbon labelled octanoic acid breath test. Gastroenterology 1993; 104: 1640-7.

7 Maes B, Hiele M, Geypens B, Rutgeerts P, Ghoos Y, Vantrappen G. Pharmacological modulation of gastric emptying rate of solids as measured by the carbon labelled octanoic acid breath test: influence of erythromycin and octanoic acid breath test: influence

8 Haycock G, Schwartz G, Wisotsky D. Geometric method for measuring body surface area: a height-weight formula validated in infants, children and adults. $\mathcal{F}$ Pediatr 1978; 93: $62-6$.

9 SAS Institute Inc. SAS/STAT User's Guide. Release 6.03 Edition 1. Raleigh, NC: SAS Institute, 1988.

10 Siegel JA, Urbain JLC, Adler LP, Charkes ND, Maurer AH, Krevsky B, et al. Biphasic nature of gastric emptying. Gut 1988; 29: 85-9.

11 Scarpignato C. Gastric emptying measurement in man. In: Scarpignato C, Bianchi Porro G, eds. Frontiers of Gastrointestinal Research. Basel: Karger, 1990: 198-246.

12 Grill BB, Lange R, Markowitz R, Hillemeier AC, McCallum RW, Gryboski JD. Delayed gastric emptying in children with Crohn's disease. F Clin Gastroenterol 1985; 7: 216-26.

13 Metges C, Wolfram G, Schmidt H-L. Oxidation rate of ${ }^{13}$ C-labelled medium chain triglycerides administered enterally or parenterally. Clin Nutr 1985; 4 (suppl): 83 .

14 Paust H, Keles T, Park W, Knoblach G. Fatty acid metabolism in infants. In: Chapman TE, Berger R, Reijngoud DJ, Okken A, eds. Stable isotopes in paediatric nutritional and metabolic research. Andover: Intercept, 1990: $1-22$.

15 Dagleish DG. Denaturation and aggregation of serum proteins and caseins in heated milk. Fournal of Agricultural and Food Chemistry 1990; 38: 1995-9.

16 Scanff P, Savalle B, Miranda G, Pelissier JP, Guilloteau P, Toullec $R$. In vivo gastric digestion of milk proteins. Effect of technological treatments. Fournal of Agricultural and Food Chemistry 1990; 38: 1623-9.

17 Nakai S, Li-Chan E. Effect of clotting in stomachs of infants on protein digestibility of milk. Food Microstructure 1987 6: $161-70$.

18 Frie MD, Khoshoo V, Secker DJ, Gilday DL, Ash JM, Pencharz PB. Decrease in gastric emptying time and episodes of regurgitation in children with spastic quadriplegia fed a whey-based formula. $\mathcal{F}$ Pediatr 1992; 120: 569-72.

19 Sturner RA, Chang KJ. Opioid peptide content of predigested infant formulas. Pediatr Res 1991; 29: A670. 20 Daniel H, Vohwinkel M, Rehner G. Effect of casein and $\beta$-casomorphins on gastrointestinal motility in rats. $\mathcal{F}$ Nutr 1990; 120: 252-7.

21 Miller MJ, Witherly SA, Clark DA. Casein: a milk protein with diverse biologic consequences. Exp Biol Med 1990: 143-59.

22 Meyer BM, Beglinger C, Jansen JB, Rovati LC, Werth BA, Hildebrand $\mathrm{P}$, et al. Role of cholecystokinin in regulation of gastrointestinal motor functions. Lancet 1989; ii: 12-4.

23 Cuber JC Bernard C, Levenez $F$, Chayvialle in lipides, protéines et glucides stimulent la sécretion de 1990; 30: 267-75.

24 Lewis LD, Williams JA. Regulation of cholecystokinin secretion by food, hormones, and pathways in the rat. $A n$ Acad Bras Cienc 1990; 258: G512-8. 